\title{
Association of Personality Traits with Oral Health Status: A Cross-Sectional Study
}

\author{
Dr. Sneha Meshram ${ }^{1}$, Dr. Deepti Gattani ${ }^{2}$, Dr. Akhilesh Shewale ${ }^{3}$, \\ Dr. Swapneel Bodele ${ }^{4}$
}

\section{ABSTRACT}

Background-Gingivitis is inflammation of gingival. The most common cause of gingivitis is poor oral hygiene. Personality is the combination of characteristics or qualities that form an individual's distinctive character. The oral health of the people may be affected by different personality characters. .The aim of the study was to assess the impact of the personality traits on oral hygiene performance and gingival health in dental OPD patients. Objectives-To assess the relationship between different personality traits with oral hygiene index score, gingival index score, plaque index score, oral hygiene practice, other habits, dental visits, income groups, education. Materials and Methods- In total 620 subjects of Department of Periodontlogy from Swargiya Dadasaheb Kalmegh Smruti dental College and Hospital, Nagpur India were selected for the study. The personality characters were assessed by using the Eysenck Personality Questionnaire Revised Short-form (EPQRS). Based on this questionnaire, the subjects were divided in to three subgroups Extroversion, Neuroticism and Psychoticism. Result-It was found that Simplified Oral Hygiene Index, Plaque Index Gingival Index was more in person with neuroticism type of personality. Conclusion -The findings of the present study suggested that there exist no co relation between various personality traits and associated oral health status. However further trials should be conducted in future to validate the present findings.

Keywords: Gingivitis, Personality, EPQRS, Extroversion, Neuroticism, Pscychoticism

Personality is the combination of characteristics or qualities that form an individual's distinctive character. The term "personality trait" refers to enduring personal characteristics that are revealed in a particular pattern of behavior in a variety of situations. The nature of personality traits can be

${ }^{1}$ Post Graduate student, Department of Periodontolgy, SDKCH Nagpur India

${ }^{2}$ HOD, Professor, Guide Department of Periodontolgy, SDKCH Nagpur India

${ }^{3}$ Senior Lecturer, Department of Periodontolgy, SDKCH Nagpur India

${ }^{4}$ Post Graduate student, Department of Periodontolgy, TK Dental college Kolhapur India

*Responding Author

Received: February 26, 2017; Revision Received: March 24, 2017; Accepted: March 29, 2017

(C) 2017 Meshram S, Gattani D, Shewale A, Bodele S; licensee IJIP. This is an Open Access Research distributed under the terms of the Creative Commons Attribution License (www.creativecommons.org/licenses/by/2.0), which permits unrestricted use, distribution, and reproduction in any Medium, provided the original work is properly cited. 


\section{Association of Personality Traits with Oral Health Status: A Cross-Sectional Study}

seen as individual predilections to show constant arrays of opinions, frame of mind, and activities. Simple tendencies are highly analytical over time, exert impact on actions, and can be used to predict future behavior. Personality has to do with individual differences among people in behavior patterns, cognition and emotion.

The study of personality started by the Greek physician Hippocrates. He developed Temperament theory into medical theory which has roots in the ancient four humors theory (460370 BC).He believed that personality is made of body fluids (humors): Blood, Yellow Bile, Black Bile and Phlegm. The explanation was further developed by his successor Galen during the second century CE. Many Researchers greatly shaped our modern theories of temperament. Hans Eysenck (1916-1997) was one of the first psychologists to analyze personality differences using a psycho-statistical method (factor analysis), and his research led him to believe that temperament is biologicallybased and consists of Extroversion, Psychoticism, Neuroticism personality component. Gordon All port was an early pioneer in the study of traits. In 1990, J.M. Digman advanced five-factor model of personality, which was extended by Lewis Goldberg. They considerd personality is broken into components called the Big Five, which are openness to experience, conscientiousness ,extroversion, agreeableness, and neuroticism (or emotionality). According to Eysenck, these components are generally stable over time, and about half of the variance appears to be attributable to a person's genetics rather than the effects of one's environment.

Different personality characteristics of people may affect the oral health.Although collective impact of social, behavioral, cultural, lifestyle, educational and economic factors have also been concerned in determining influence of personality characteristics on oral health status. It is considered that the age, gender, smoking habits, anxiety, stress, depression in everyday life, selfliking was positively related to the oral health behaviour. Thomson et al suggested that personality may be related to the oral health as it increases risk of oral disease and alters the individuals' attitude towards the disease.

In the field of dentistry several studies have demonstrated a relationship between Quality of Life and patient personality. Van Waas et al. described a relationship between patient satisfaction and psychological factors in wearers of complete dentures. Kressin et al. concluded that negative affectivity, which is a general disposition to experience subjective distress, was significantly associated with Oral Hygiene Related Quality Of Life ratings in a study of older men. Another study found that different personality component may influence dental perceptions and play a significant role in shaping satisfaction with dentition in younger people.

Brief cognitive interventions can alter the attitudes and values tapped into by personality traits, which might be useful in preventive dentistry. The number of environmental, physical and psychological factors has the potential to alter the gingival tissues and host immune responses 


\section{Association of Personality Traits with Oral Health Status: A Cross-Sectional Study}

resulting in more severe periodontal disease expression. Also there is impact of overall personality of an individual on person's oral hygiene condition. Hence, the present study was done to assess the impact of this personality trait on oral hygiene performance and gingival health.

\section{MATERIALS AND METHODS}

\section{Participants}

This study was approved by the institutional ethical committee Swargiya Dadasaheb Kalmegh Smruti Dental College and Hospital, Nagpur India .Total 620 outpatients visiting to the Department of Periodontology from January 2016 to March 2016 were invited to participate in the present study. The inclusion criteria were 1) Minimum age of 18 years of both the genders 2) Minimum 20 permanent teeth.(with at least index teeth for indices) 3) subjects who are not under professionally monitored plaque control program. The exclusion criteria were subjects having any 1) systemic illness Patients with a history of a systemic condition or medication use that might influence the gingival condition were excluded (i.e. patients with a history of diabetes mellitus, thyroid diseases, chronic renal problems 2) subjects under steroids, NSAIDS, antibiotics etc.3) Pregnancy 4) Subjects who have not answered the complete questionnaire 5) Mentally retarded subjects.

A total of 1200 subjects visited to the Periodontology Department OPD during the study period. Of these, 900 subjects met the inclusion criteria 620 subjects were agreed to participate in the study. (The Sample size of 620 subjects was obtained by the formula $n=4 \mathrm{pq} / \mathrm{L}^{2}$ where $\mathrm{p}=$ population proportion to positive character, $\mathrm{q}=1-\mathrm{p}$ and $\mathrm{L}=$ allowable error.), 95\%confidence level and $90 \%$ power reference value.)

\section{Data Collection}

After the informed consent had been obtained eligible subjects provided the designed proforma. In the proforma questionnaire sought of information Name, Age, Sex, Dental visits, Oral hygiene Habit-Brushing aid and frequency, other habits, Income groups (National council Of Applied Economical Research), Education were obtained. Subjects were assured that their answers would be held strictly confidential to encourage complete and truthful self-reporting. In the clinical examination OHI-S index, Plaque Index, gingival Index was recorded to evaluate oral hygiene and gingival status of the subject. Plaque was recorded using an index developed by Silness and Loe 1964, Simplified Oral Hygiene Simplex index by Greene and Vermillion 1964.The full mouth gingival index (GI) of Loe and Silness 1963 was used to record gingival inflammation around the entire dentition (excluding 3rd molars)

\section{Personality assessment}

The personality characters were assessed by using the Eysenck Personality Questionnaire Revised Short-form (EPQR-S; Eysenck et al ,1985).EPQR-S is self-reported questionnaire each 


\section{Association of Personality Traits with Oral Health Status: A Cross-Sectional Study}

question has binary response- 'yes', 'no'. For complete understanding and better response, questionnaire was provided in English-Hindi language. Each dichotomous item will be scored maximum ' 1 ' and minimum ' 0 ' possible score. EPQR-S includes 48 items and 4 subscales: Extroversion (E-12 items), Neuroticism (N-12 items), Psychotics P-912 items) and Lie (L-12 items). As an individual can have more than one personality trait, based on this models, the subjects who scored above average expressed greater forte of that particular factor and to be considered into that personality trait. Accordingly subjects were divided into three groups: P, E, and $\mathrm{N}$, respectively. For reliability of the answers given, a Lie scale was performed. Those who scored more than the average score in lie scale were excluded from the study. Lie scales were originally introduced into personality measures in order to detect the "faking good" of scores on other scales (O'Donovan, 1969). According to Eysenck and Eysenck (1976) the lie scale included in the Eysenck Personality Questionnaire allows lying to be diagnosed when a set of rarely performed acts are permitted by the respondent as being habitually done and when frequently performed non-desirable acts are denied by the respondent.

Extroversion (E) describes the personality as Sociable, Impulsive, Like excitements, Sensation seeking, Cheerful, Self-confident, Enthusiastic and Active person with high Extraversion are energetic, talkative, social, and dominant whereas, person with low Extraversion tend to be soft, peaceful, reserved, and passive to other. Neuroticism (N) refers to the personality with Emotional instability ,Impulsiveness or possessiveness ,Excessive panic, anxiety, Low selfrespect, overly sentiments, Feeling of guilt ,Depression ,Irritability, Tension, shyness. According to Eysenck's (1967) theory of personality, neuroticism is interlinked with low tolerance for stress or aversive stimuli. Those who score high in neuroticism are emotionally sensitive and susceptible to stress. They are more likely to take ordinary situations as threatening and minor frustrations as miserably challenging and they are often in a bad mood.

Psychoticism (P) personalities are non-conformist, tough minded, willing to take risks, Unconcerned about the rights and welfare of others, may engage in antisocial behaviors and liking odd and unusual things.

\section{Statistical Analysis}

The data was analysed with the help of M.S. Excel and Epi-info software version 7.1.1.14.Chi square test was applied and $\mathrm{p}$ value of $<0.05$ was considered to be significant.

\section{RESULTS}

620 subjects were given the questionnaire, and explained to those who were not understood the questions. After lie scale 40 subjects were excluded from the study. So the final sample size was 580 subjects. Due to multiple personality in the subject; total 636 personality traits were calculated. In relation to 636 personality traits clinical and other parameter were statistically analyzed .178 personalities of mean age 35.23 years were belonged to Psychoticism, among 
them117 male and 61 female. In Neuroticism total 229 personalities were involved of mean age 35.56years, 134 were male and 95 were female. 229 personalities, 134 male and 95 female of mean age 33.85years were belonged to Extroversion. (As shown in table -1)

Most of the personalities who had never visit the dental clinic were belong to extroversion and Neuroticism group. Most of the personalities were brush their teeth once a day with toothbrushtoothpaste. Most of The personalities had habit of chewing tobacco.

The personalities in group Extroversion and Neuroticism were from lower middle and middle income groups. It was found that Simplified Oral Hygiene Index, Plaque Index Gingival Index was more in person with neuroticism type of personality

Table 1: The mean age and gender in all groups

\begin{tabular}{|l|l|l|l|l|}
\hline PERSONALITY & Mean Age (Years) & Males (\%) & Females (\%) & Total (\%) \\
\hline P & 35.23 & $117(30.06)$ & $61(24.73)$ & $178(27.96)$ \\
\hline N & 35.65 & $134(34.96)$ & $95(37.63)$ & $229(36.01)$ \\
\hline E & 33.85 & $134(34.96)$ & $95(37.63)$ & $229(36.01)$ \\
\hline Total & & $385(60.59)$ & $251(39.40)$ & $636(100)$ \\
\hline
\end{tabular}

Table 2: Association of Personality traits with various dental factors

\begin{tabular}{|c|c|c|c|c|c|}
\hline Factors & $\mathbf{P}(\%)$ & E (\%) & $\mathbf{N}(\%)$ & $X^{2}$ & P value \\
\hline \multicolumn{6}{|l|}{ Dental Visits } \\
\hline Once & 28.79 & 24.71 & 23.53 & 1.28 & 0.97 \\
\hline more than twice & 13.64 & 10.59 & 14.12 & & \\
\hline Never & 27.97 & 36.01 & 36.01 & & \\
\hline \multicolumn{6}{|l|}{ Brushing Frequency } \\
\hline Once & 60.61 & 58.82 & 65.88 & 1.37 & 0.967 \\
\hline Twice & 30.30 & 32.94 & 28.24 & & \\
\hline Thrice & 9.09 & 8.24 & 5.88 & & \\
\hline \multicolumn{6}{|l|}{ Brushing Aid } \\
\hline Toothbrush+ Toothpaste & 71.21 & 64.71 & 69.41 & 2.86 & 0.83 \\
\hline Toothbrush+Toothpowder & 12.12 & 17.65 & 15.29 & & \\
\hline Other & 16.67 & 17.65 & 15.29 & & \\
\hline \multicolumn{6}{|l|}{ Habits } \\
\hline Tabacco & 25.53 & 31.91 & 42.55 & 2.086 & 0.554 \\
\hline Pan & 26.08 & 39.13 & 34.78 & & \\
\hline Smoking & 22.22 & 38.88 & 38.88 & & \\
\hline Alcohol & 28.57 & 35.71 & 35.71 & & \\
\hline \multicolumn{6}{|l|}{ Income Group } \\
\hline Low & 22.22 & 33.33 & 44.44 & 7.73 & 0.81 \\
\hline Lower Middle & 27.39 & 38.35 & 34.24 & & \\
\hline
\end{tabular}


Association of Personality Traits with Oral Health Status: A Cross-Sectional Study

\begin{tabular}{|c|c|c|c|c|c|}
\hline Factors & $\mathbf{P}(\%)$ & E (\%) & $\mathrm{N}(\%)$ & $\mathrm{X}^{2}$ & P value \\
\hline Middle & 30.13 & 35.61 & 34.24 & & \\
\hline Upper Middle & 30 & 36 & 34 & & \\
\hline High & 23.07 & 30.76 & 46.15 & & \\
\hline \multicolumn{6}{|l|}{ Education } \\
\hline Illiterate & 3.03 & 2.35 & 4.71 & 8.09 & 0.78 \\
\hline Upto Secondary School & 18.18 & 23.53 & 25.88 & & \\
\hline Below Secondary School & 40.91 & 43.53 & 42.35 & & \\
\hline Graduate & 36.36 & 27.06 & 25.88 & & \\
\hline Post- Graduate & 1.52 & 3.53 & 1.18 & & \\
\hline \multicolumn{6}{|l|}{ OHI-S } \\
\hline Good & 33.34 & 33.33 & 33.33 & 4.08 & 0.67 \\
\hline Fair & 23.91 & 41.30 & 34.78 & & \\
\hline Poor & 28.88 & 32.22 & 38.88 & & \\
\hline \multicolumn{6}{|l|}{ Plaque Index } \\
\hline Excellent & 32.25 & 38.70 & 29.03 & 7.29 & 0.61 \\
\hline Good & 31.66 & 33.33 & 35.00 & & \\
\hline Fair & 25.64 & 39.31 & 35.04 & & \\
\hline Poor & 25.00 & 25.00 & 50.00 & & \\
\hline \multicolumn{6}{|l|}{ Gingival Index } \\
\hline Mild & 36.36 & 30.90 & 32.72 & 10.18 & 0.11 \\
\hline Moderate & 27.86 & 38.52 & 33.60 & & \\
\hline Severe & 20.33 & 35.59 & 44.06 & & \\
\hline
\end{tabular}

\section{DISCUSSION}

Gingivitis is a non-destructive periodontal disease that causes irritation, redness and swelling of the gingival and if not controlled, it can progress to periodontitis, where the inflammation results in tissue destruction and alveolar bone resorption, which can ultimately lead to tooth morbidity.

The different personality instruments have been designed to examine, different personalities in individual and their differences in emotional and behavioral style. Personality tests/scale scan be a useful tool to articulate the characteristic about personality in individual also it help to describe the personality. Few scales are -Hardiness Scale, Courtauld Emotional control scale, Subjective scale of perceived social support, Multidimensional scale of perceived support (MSPSS), Life event scale etc.

Since the advance of Eysenck personality theory, various measures were developed in order to assess the various personality traits. The early Maudsley Medical Questionnaire(MMQ) contains 40 items (Eysenck ,1952), Mauddsley Personality Inventionary (MPI) contains 48 items (Eysenck ,1959),The Eysenck personality Inventionary (EPI) contains 57 items (Eysenck and Eysenck 1964),The Eysenck personality questionnaire (EPQ) contains 90 items (Eysenck and Eysenck 1975)and the revised Eysenck Personality questionnaire (EPQR) contains 100 items

(C) The International Journal of Indian Psychology, ISSN 2348-5396 (e)| ISSN: 2349-3429 (p) | 66 


\section{Association of Personality Traits with Oral Health Status: A Cross-Sectional Study}

(Eysenck, Eysenck and Barrett, 1985), Eysenck Personality Questionnaire Revised Short form (EPQRS) contains 48 items (Eysenck 1985).

While determining different personality traits, even among all questionnaires were reliable and applicable; however there is some practical disadvantages in using long tests. due to the length of sentence-based and some lexical measures, short forms of personality questionnaire have been developed and validated for use in applied research settings where questionnaire space and respondent time are limited such as EPQR-S (48 items). Now it been used widely. Trambek Tiwari et al 2009 suggested that EPQR-S is a reliable scale for the measurement of various personality traits. However some research suggested that because of its insufficient length it fails to provide adequate detail to evaluate personality.

In the present study Plaque index, OHI-S index were used assess the oral hygiene performance and Gingival index were employed to assess the influence of personality traits on gingival health. Research into the association between personality and Oral health has shown at least three processes to be involved. First, the individual with dominant aggressive personality character shows poor oral health because of bruxism. Second, individuals who are low on constraint might be more likely to smoke it may predispose to poor oral health and ultimately leads to periodontitis. Third, highly stressful individual might tend to interpret oral symptoms as being more disastrous than would their low-scoring in stress character.

Capsi A. et al 2005 indicated that individuals who scores highly on Psychoticism scale are more aggressive which predisposes poor oral health as most of them having habit of Bruxism. And subjects who scores low in Extroversion are more likely to smoke which affects the periodontium leading to Periodontitis. Although it was long assumed that personality traits remain stable and unchanging, longitudinal research has documented that personality can and does change markedly, probably because of life experiences and lessons encountered in young adulthood.

In the present study it was observed that as there is certain association is present between personalities with oral hygiene and gingival health but no statistically significant difference exists amongst the traits $(\mathrm{P}, \mathrm{E}, \mathrm{N})$ in relation to Simplified oral hygiene index, Gingival index, plaque index also with oral hygiene practice, other habits, dental visits, income groups, education .This finding is similar in relation gingival health to the Rajesh K.S.et al 2013 who Observed no statistically significant relation between personality traits and gingival health status of the subjects. However it was observed that use of tobacco was more and brushing frequency was less in certain personality. ${ }^{16}$ The study by Thomson et al 2011 aimed to describe the association between personality characteristics and self-reported oral health in a longstanding cohort study. It has found a consistent association between negative emotionality and poorer self- 


\section{Association of Personality Traits with Oral Health Status: A Cross-Sectional Study}

reported oral health, whether measured using a sophisticated scale or a single-item global measures.

Nikias et al. (1977) stated that when the Economic status was controlled for, lower educational level appeared, in their sample, to be related to poor oral hygiene, tooth loss, and periodontal disease Paulandar et al 2003 concluded that Educational level was shown to influence the oral conditions and should be considered in assessing risk, and in planning appropriate preventive measures.

As far the author knowledge this study is the first to observe the parameters such Education, Income, HI-S, Plaque index in association with different personalities. As it was seen that these factors could be a possible confounding factor in association with the study.

\section{CONCLUSION}

The findings of the present study suggested that there exist no co relation between various personality traits and associated oral health status. However further trials should be conducted in future to validate the present findings.

\section{Acknowledgments}

The author appreciates all those who participated in the study and helped to facilitate the research process.

Conflict of Interests: The author declared no conflict of interests.

\section{REFERENCES}

Carlson, Neil, et al. 2010. Psychology the Science of Behaviour, p. 438. Pearson Canada, United States of America.

Caspi A, Roberts B, Shiner R. Personality development: stability and change. Annu Rev Psychol 2005; 56: 453-484

Chris J. Jackson a, Leslie J. Francis b. Interpreting the correlation between neuroticism and lie scale scores. Personality and Individual Differences26(1999)59-63

Eysenck, H. J., \& Eysenck, M. W. (1985). Personality and individual differences: A natural science approach. New York: Plenum

Goldberg, L. R. (1993). "The structure of phenotypic personality traits". American Psychologist 48 (1): 26-34.

Gosling, Samuel D; Rentfrow, Peter J; Swann, William B (2003).A very brief measure of the Big-Five personality domains. Journal of Research in Personality 37 (6): 504-28.)

Hajime Takeshita , Kazunori Ikebe , Ryosuke Kagawa et al. Association of personality traits with oral health-related quality of life independently of objective oral health status: A study of community-dwelling elderly Japanese. Journal of dentistry 43 (2015)342 - 349.

(C) The International Journal of Indian Psychology, ISSN 2348-5396 (e)| ISSN: 2349-3429 (p) | 68 
Association of Personality Traits with Oral Health Status: A Cross-Sectional Study

Mischel, W., Shoda, Y., \& Smith, R. E. (2004). Introduction to personality: Toward an integration. New York: John Wiley \& Sons.).

Nikias, M.K. Fink, R and Sollecito, W. Oral health status in relation to socioeconomic and ethnic characteristics of urban adults in the U.S.A. Commun Dent Oral Epi 1977; 5: 200206

Norris, C. J.; Larsen, J. T.; Cacioppo, J. T. (2007).Neuroticism is associated with larger and more prolonged electro dermal responses to emotionally evocative pictures. Psychophysiology 44 (5): 823-826.

Paulander J, Axelsson P, Lindhe J: Association between level of education and oral health status in 35-, 50-, 65- and 75-year-olds. J Clin Periodontol 2003; 30: 697-704.

Rajesh Kashyap Shanker, Munaz Mohamed, Shashikanth Hegde et al. Influence of personality traits on gingival health. Journal of Indian Society of Periodontology - Vol 17, Issue 1, Jan-Feb 2013

Roberts B, Walton K, Viechtbauer W. Patterns of mean level change in personality traits across the life course: a meta-analysis of longitudinal studies. Psychol Bull 2006; 132:

Shiner, R.; Caspi, A. (2003).Personality differences in childhood and adolescence: Measurement, development, and consequences". Journal of Child Psychology and Psychiatry 44 (1): 2-32.

Storm Paula, "Personality Psychology and the Workplace", MLA Forum, 2006

Thomson WM, Caspi A, Poulton R, Moffitt TE, Broadbent JM Personality and oral health. Eur J Oral Sci 2011;119:366-72.

Tracie M. Umaki,* Michael R. Umaki,†and Charles M. Cobb. (Review The Psychology of Patient Compliance: A Focused Review of the Literature. J Periodontol 2012;83:395400.

Trambak Tiwari, Anju L.Singh, Indramani L.Singh. The short form revised Eysenck personality questionnaire :A hindi edition (EPQRS-H),Jan-jun 2009:(18); 27-31.)

\section{Questionnaire}

1) Does your mood often go up and down?

Yes / No

2) Do you take much notice of what people think?

3) Are you a talkative person?

4) If you say you will do something, do you always keep your promise no matter how inconvenient it might be?

5) Do you ever feel just miserable for no reason?

6) Would being in debt worry you?

7) Are you rather lively?

8) Were you ever greedy by helping yourself to more than you share of anything?

9) Are you an irritable person?

10) Would you take drugs which may have strange are dangerous effects?

11) Do you enjoy meeting new people? 
12) Have you every blamed someone for doing something you knew was really fault?

13) Are you filings easily hurt?

14) Do you prefer to go your own way rather than act by the rules?

15) Can you usually let yourself go and enjoy yourself at lively party?

16) Are all your habits good and desirable ones?

17) Do you often feel fed-up?

18) Do good manners and cleanliness matter much to you?

19) Do you usually take the initiative in making new friends?

20) Have you ever taken anything (even a pin or button) that belonged to someone else?

21) Would you call yourself a nervous person?

22) Do you think marriage is old -fashioned and should be done away with?

23) Can you easily get some life into a rather dull party?

24) Have you ever broken or lost something belonging to someone else?

25) Are you a worrier?

26) Do you enjoy co - operating with other?

27) Do you tend to keep in the background on social occasions?

28) Dose it worry you if you know there are mistakes in your work?

29) Have you ever said anything bad or nasty about anyone?

30) Would you call yourself tense or highly strung?

31) Do you think people spend too much time safeguarding their future with saving and insurance?

32) Do you like mixing with people?

33) As a child were you every cheeky to your parents?

34) Do you worry too long after an embarrassing experience?

35) Do you try not be rude to people?

36) Do you like plenty of bustle and excitement around you?

37) Have you ever cheated at a game?

38) Do you suffer from nerves?

39) Would you like other people to be afraid of you?

40) Have you ever taken advantage of someone?

41) Are you mostly quiet when you are with other people?

42) Do you often feel lonely?

43) Is it better to follow society's rules than go your own way?

44) Do other people think of you as being very lively?

45) Do you always practice what you preach?

46) Are you often troubled about feeling of guilt?

47) Do you sometimes put off until tomorrow what you ought to do today?

48) Can you get a party going? 
Association of Personality Traits with Oral Health Status: A Cross-Sectional Study

\section{Scoring Key for EPQR-S}

- For items-2,6,8,12,18,20,24,26,27,28,29,33,35,37,40,41,43 and47 Yes=0

- $\quad$ Foritems1,3,4,4,7,9,10,11,13,14,15,16,17,19,21,22,23,25,30,31,32,34,36,38,39,42,44,45,46 ,48 Yes=1

- Neuroticism-1,5,9,13,17,21,25,30,34,38,42,46

- Extroversion-3,7,11,15,19,23,27,32,36,41,44

- Psychoticism-2,6,10,14,18,22,26,28,31,35,39,43

- $\quad$ Lie-4,8,12,16,20,24,29,33,37,40,45,47.

How to cite this article: Meshram S, Gattani D, Shewale A, Bodele S (2017), Association of Personality Traits with Oral Health Status: A Cross-Sectional Study, International Journal of Indian Psychology, Volume 4, Issue 2, No. 95, ISSN:2348-5396 (e), ISSN:2349-3429 (p), DIP:18.01.167/20170402, ISBN:978-1-365-84231-3 